\title{
Autism and pervasive developmental disorders
}

\author{
Carlos A. Gadia1, Roberto Tuchman², Newra T. Rotta ${ }^{3}$
}

\begin{abstract}
Objective: To review the current knowledge on neurobiological aspects of autism and pervasive developmental disorders, as well as to provide pediatricians with up to date information on diagnosis and treatment of autism.

Sources of data: Review of MEDLINE and Internet.

Summary of the findings: Autism is the 3rd developmental disorder, with an incidence of 40 to $130 / 100,000$ individuals. Diagnosis is based on clinical findings, following DSM IV criteria. Neuroimaging, investigation of fetal neurological status, and genetic investigation contribute towards a better understanding of the neurobiology of autism.
\end{abstract}

Conclusion: Pediatricians are the first health professional to come in contact with patients with autism. Thus, they should be able to diagnose and to coordinate the multidisciplinary treatment of these patients.

J Pediatr (Rio J). 2004;80(2 Suppl):S83-S94: Autism, child behavior, child development.

\section{Definition}

The term autism was first used by Bleuler in 1911 to designate loss of contact with reality, which caused great difficulty in or incapacity of communication. ${ }^{1}$

Kanner, in 1943, used the same term to describe 11 children who shared quite an original behavior. He suggested that autism was an innate inability to establish affective and interpersonal contact and believed that it constituted an extremely rare syndrome, which was more frequent ${ }^{2}$ than expected, due to the small number of diagnosed cases. In 1944, Asperger described cases with some characteristics that were similar to autism,

1. Associate director, Dan Marino Child Nett, Dan Marino Center, Miami Children's Hospital. Assistant professor, Department of Neurology, School of Medicine, University of Miami.

2. Medical director, Dan Marino Center, Miami Children's Hospital. Assistant professor, Department of Neurology, School of Medicine, University of Miami.

3. Associate professor, Department of Pediatrics, School of Medicine, Universidade Federal do Rio Grande do Sul (UFRGS). Chief of the Unit of Children's Neurology, Service of Pediatrics, Hospital de Clínicas de Porto Alegre (HCPA), Porto Alegre, RS, Brazil. which included difficulty in social communication in children with normal intelligence. ${ }^{3}$

Autism is not a single entity, but a complex developmental disorder that is behaviorally defined, with multiple etiologies, and varying levels of severity. ${ }^{3}$ The phenotypic presentation of autism may be influenced by associated factors that do not necessarily belong to the major characteristics that define this disorder. Cognitive skill is an important factor to be considered. ${ }^{4-9}$

Behavioral symptoms that define autism include qualitative deficit in social interactions and in communication, repetitive and stereotyped behaviors and a limited repertoire of interests and activities. ${ }^{1}$ The variation in levels of social and communication skills and behavioral patterns that occur in autistic patients is now more appropriately termed pervasive developmental disorders (PDD). 10

Based on Kanner's description, numerous studies involving the epidemiology, classification and identification of autism have significantly contributed to the elucidation of biological aspects of PDD. $3-7,10-12$ 
Difficulties in social interaction in PDD may be characterized by withdrawal or improper social behavior; poor eye contact; difficulty in participating in group activities; blunting of affect, or inappropriate demonstration of emotions; lack of social or emotional empathy. As these individuals reach adulthood, social withdrawal is reduced, but poor social skills and difficulty making friends still persist.

Adolescents and adults with autism misinterpret how they are perceived by others, and autistic adults, even with appropriate cognitive skills, tend to alienate themselves.

Communication disorders occur in varying degrees, compromising both verbal and nonverbal ability to share information with others. Some children do not develop communication skills, whereas others show immature language characterized by jargon, echolalia, pronoun reversal, abnormal prosody, monotonous intonation, etc. Those with appropriate capacity to express themselves may be unable to start or maintain a conversation. Language and communication disorders persist in adulthood, and a significant number of autistic patients remain nonverbal. Those who acquire verbal skills may have persistent difficulty in establishing a conversation, such as lack of reciprocity, difficulty in understanding language subtleties, jokes or sarcasm, as well as problems with interpreting body language and facial expressions.

Repetitive and stereotyped behaviors, characteristic of autism, include reluctance to changes, insistence on certain routines, excessive attachment to objects, fascination with spinning objects (e.g.: wheels or propellers). Although some children seem to play, they are more concerned about aligning or handling toys than using them for a symbolic purpose. Motor and verbal stereotypies such as swinging, clapping repeatedly, walking in circles or repeating certain words, sentences or songs also are frequent among autistic individuals. Autistic adults show improved adaptation to changes, but limited interests persist, and those with appropriate cognitive skills tend to concentrate their interests in restricted topics, such as train/airplane timetables, maps or historical facts, which rule their lives.

In the absence of a biological marker, the diagnosis of autism and the determination of its "borders" is still a somewhat arbitrary clinical decision. If the current criteria for autism are used, we will see that autism is not actually a rare disorder. Depending on the inclusion criteria, the prevalence of autism ranges from 40 to 130 per $100,000,12,13$ ranking third among developmental disorders, outranking congenital malformations and Down's syndrome. Recent studies suggest that the prevalence of PPD may be of two to five per $1,000,14$ which led to a speculation about an "epidemic" of PPD. It is unclear whether the prevalence of PPD has really increased; it is very likely that the increase in the number of diagnosed individuals is due to the better identification of these disorders in less severely affected children and to differences between DSM-III and DSM-IVR diagnostic criteria $^{15}$ (Table 1 ).

Table 1 - Prevalence of neurological disorders (per 100,000)*

\begin{tabular}{lc}
\hline Epilepsy & 650 \\
Brain paralysis & 250 \\
Dementia & 250 \\
Parkinson's Disease & 200 \\
Autism & 130 \\
Congenital malformation $\mathrm{CNS}^{\dagger}$ & 70 \\
Down syndrome & 50
\end{tabular}

* Adapted from Kurtzke. ${ }^{15}$

$\dagger \mathrm{CNS}=$ central nervous system.

\section{Diagnosis}

The current criteria used to diagnose autism are those described in the Diagnostic and Statistical of the American Psychiatric Association (DSM) ${ }^{10}$ (Table 2).

These criteria have improved with time. Up to 1980, autism was not considered to be a different entity from schizophrenia. In 1987, the DSM-III-R established diagnostic criteria for development-related disorders, with two diagnoses being established under the name of pervasive (or global) developmental disorder: (1) autism; and (2) pervasive (or global) developmental disorder, not otherwise specified (PPD-NOS). In practice, (PPD) or autism spectrum disorders (ASD) have been used as diagnostic categories in individuals with poor social interaction, communication/language difficulties and repetitive behaviors. The DSM-IV criteria for autism have a high level of specificity and sensitivity in different age groups and between individuals with distinct language and cognitive skills. ${ }^{16}$

Nonetheless, it is necessary to identify subgroups of autistic individuals for practical purposes and research. The subdivisions established by the DSM-IV, under the general name of PPD, are an attempt to meet the scientific needs of research and to allow the development of services that fulfill the needs of individuals with autism and related disorders ${ }^{17}$ (Tables 3, 4 and 5).

Although it is now easier to understand each of the PPD using the DSM-IV criteria, whether autism and Asperger's syndrome are different clinical entities or variations of the same disorder; and whether the disintegrative disorder is a valid diagnostic entity, are issues that have not been solved yet. ${ }^{17}$ On top of that, the inclusion of Rett's syndrome in the general category of PPD should be interpreted only as the observation that girls with this syndrome have a behavior similar to 
Table 2 - Diagnostic criteria for autistic disorder (DSM-IV, 1994)

A. At least six items from the 12 following criteria, with two from (1), and at least one from (2) and (3):

1) Qualitative impairment in social interaction, as manifested by:

a. marked impairment in the use of multiple nonverbal behaviors

b. failure to develop peer relationships appropriate to developmental level

c. a lack of spontaneous seeking to share enjoyment, interests, or achievements with other people

d. lack of social or emotional reciprocity

2) Qualitative impairments in communication, as manifested by:

a. delay in, or total lack of, the development of spoken language (not accompanied by an attempt to compensate through alternative modes of communication such as gesture or mime)

b. in individuals with adequate speech, marked impairment in the ability to initiate or sustain a conversation with others

c. stereotyped and repetitive use of language or idiosyncratic language

d. lack of varied, spontaneous make-believe play or social imitative play appropriate to developmental level

3) Restricted, repetitive, and stereotyped patterns of behavior, interests, and activities:

a. encompassing preoccupation with one or more stereotyped and restricted patterns of interest that is abnormal either in intensity or focus

b. apparently inflexible adherence to specific, nonfunctional routines or rituals

c. stereotyped and repetitive motor mannerisms

d. persistent preoccupation with parts of objects

B. Delays or abnormal functioning in at least one of the following areas, with onset prior to age 3 years.

C. The disturbance is not better accounted for by Rett's disorder or childhood disintegrative disorder.

that of autistic girls. The principal aim of the criteria proposed for the diagnosis of autism and related disorders is to minimize the discrepancies between researchers and clinicians with regard to the definition of these disorders at the behavioral (typology) or biological (etiology) level (Table 6).

Table 3 - DSM-IV subgroups for pervasive developmental disorders

Autism

Rett's syndrome

Childhood disintegrative disorder

Nonspecific pervasive developmental disorder

Asperger's syndrome
Table 4 - Diagnostic criteria for Asperger's syndrome

A. Qualitative impairment in social interaction, as manifested by at least two of the following:

1) marked impairments in the use of multiple nonverbal behaviors such as eye-to-eye gaze, facial expression, body posture, and gestures to regulate social interaction

2) failure to develop peer relationships appropriate to developmental level

3) a lack of spontaneous seeking to share enjoyment, interest or achievements with other people, (e.g.. by a lack of showing, bringing, or pointing out objects of interest to other people)

4) lack of social or emotional reciprocity

B. Restricted repetitive \& stereotyped patterns of behavior, interests and activities, as manifested by:

1) encompassing preoccupation with one or more stereotyped and restricted patterns of interest that is abnormal either in intensity or focus

2) apparently inflexible adherence to specific, nonfunctional routines or rituals

3) stereotyped and repetitive motor mannerisms

4) persistent preoccupation with parts of objects

C. The disturbance causes clinically significant impairments in social, occupational, or other important areas of functioning

D. There is no clinically significant general delay in language (E.G. single words used by age 2 years, communicative phrases used by age 3 years)

E. There is no clinically significant delay in cognitive development or in the development of age-appropriate self help skills, adaptive behavior (other than in social interaction) and curiosity about the environment in childhood.

F. Criteria are not met for another specific Pervasive Developmental Disorder or Schizophrenia

Table 5 - Diagnostic criteria for Childhood Disintegrative Disorder

A. Apparently normal development for at least the first 2 years after birth as manifested by the presence of age-appropriate verbal and nonverbal communication, social relationships, play, and adaptive behavior

B. Clinically significant loss of previously acquired skills (before age 10 years) in at least two of the following areas:

1) expressive or receptive language

2) social skills or adaptive behavior

3) bowel or bladder control

4) play

5) motor skills

C. Abnormalities of functioning in at least two of the following areas:

1) qualitative impairment in social interaction (e.g., impairment in nonverbal behaviors, failure to develop peer relationships, lack of social or emotional reciprocity)

2) communication (e.g., delay o language development, inability to initiate or sustain a conversation, stereotyped, repetitive and idiosyncratic use of language, lack of varied and spontaneous play)

3) restricted, repetitive, and stereotyped patterns of behavior, interests, and activities, including motor stereotypes and mannerisms

D. The disturbance is not better accounted for by another specific Pervasive Developmental Disorder or by Schizophrenia. 
Table 6 - Pathologies potentially associated to autism

\begin{tabular}{ll}
\hline Congenital/Acquired & Genetic/Metabolic \\
\hline Measles & $\begin{array}{l}\text { Chromosomal abnormalities } \\
\text { (Fragile X etc.) }\end{array}$ \\
Toxoplasmosis & Tuberous sclerosis \\
Citomegalovirus & Neurofibramatosis \\
Moebius syndrome & Leber's congenital amaurosis \\
Hypomelanosis of Ito & Phenylketonuria \\
Dandy-Walker syndrome & Histidinemia \\
Cornelia de Lange syndrome & Ceroid lypofuscinosis \\
Soto syndrome & Coeliac disease \\
Goldenhar syndrome & Disorder of purine \\
& metabolism \\
Williams syndrome & Adrenoleukodystrophy \\
Microcephalia & Duchenne muscular \\
& distrophy \\
Hydrocephalia & Angelman syndrome \\
Joubert Syndrome & \\
Encephalitis/Meningitis & \\
West syndrome & \\
Lead intoxication & \\
Cerebellum's meduloblastoma & \\
surgery & \\
\hline
\end{tabular}

The discovery of the gene responsible for $80 \%$ of cases of Rett's syndrome (MECP2), 18 with all the possible consequences on the study of neurobiological processes and on the identification of basic mechanisms of neurodevelopmental disorders, reinforces the idea that it is important to establish homogeneous subgroups. The diagnosis of an associated medical or neurological condition in an autistic individual defines the clinical symptoms at the neurobiological level, but does not rule out the diagnosis of autism, which is defined at the behavioral level. An example would be that of a person with behaviors that meet the criteria for the diagnosis of autism and has a chromosome analysis that shows fragile $X$ syndrome. In this case, behavioral symptoms would be consistent with the diagnosis of autism (with all implications in terms of management and prognosis) and the biological cause for this behavioral syndrome would be the fragile $X$ syndrome (with all consequences in genetic and prognostic terms). It is still unclear whether the new criteria established by the DSM-IV for PDD will manage to achieve this goal.

The different diseases associated with PDD support the hypothesis that behavioral symptoms that define this complex of symptoms may be secondary to a wide variety of brain insults. The heterogeneity of these disorders may be due to distinct etiologies or to a combination of factors, such as etiology, genetic susceptibility, and environmental factors. The association between autism and tuberous sclerosis (TE) is particularly interesting. The prevalence of TE in autistic individuals is of $1-4 \%$ (significantly higher than that of the fragile $X$ syndrome and autism), while $25 \%$ of TE patients are autistic and $40-50 \%$ meet the criteria for PDD. This association is probably due to abnormal organization of the brain related to TE genes - TSC1 on chromosome 9 q34 and TSC2 on 16 p13.3 and/or to complications of $T E$, such as mental retardation and severe epilepsy in the first year of life (West syndrome). 19

Even when autistic disorders are properly diagnosed using appropriate diagnostic criteria, the symptomatic profile varies considerably, depending on the underlying etiology. 20 The diagnosis of autism requires a careful clinical assessment: language and neuropsychological evaluation, in addition to additional exams (e.g.: chromosome studies including DNA for fragile $X$ syndrome and neuroimaging or neurophysiological studies, whenever necessary), may be useful in specific cases to identify more homogeneous subgroups, according to the behavioral phenotype and etiology. This will allow us to understand the pathophysiology of these disorders and to establish more specific interventions and prognoses.

The screening of autistic individuals requires a multidisciplinary team and the use of objective scales. Structured techniques should be used to assess children's social behavior (joint attention, eye contact, facial expression, and affect) and their capacity to imitate. The Childhood Autism Rating Scale (CARS) ${ }^{21}$ is one of the most commonly used scales, consisting of a structured 15-item questionnaire (applicable in 30-45 minutes) answered by the parents or surrogates of an autistic child older than two years. A seven-point score is used for each of the 15 items, which allows the classification of autism into mild/moderate or severe.

The Vineland adaptive behavior scale is also commonly used. It is used to measure social development in a healthy population, which may be compared to that of autistic individuals. ${ }^{22}$

The two most comprehensive batteries of psychological tests used for the diagnosis of autism, especially in research, are the autism diagnostic observation schedule (ADOS) and autism diagnostic interview (ADI). Together, they represent a complete structured interview and an observation method for the objective assessment of social skills, communication skills, and behavior of autistic individuals, ranging from speechless children to adults who are able to communicate relatively well. ${ }^{23-25}$ Its use became a standard in research studies on autism in the 1990s. A recent study investigated specific deficits in "social communication" in ASD children using ADOS, and three factors were identified: joint attention, affective reciprocity, and mind theory. 26 These three communication domains are central to social growth in typical children, and if not properly developed, they are responsible for basic deficits in the spectrum of social communication disorders. 


\section{Neuropathology and neuroimaging}

Currently, the neuropathology of autism is based on Bauman \& Kemper, ${ }^{27-29}$ who obtained consistent neuropathological findings in the limbic system and in cerebellar circuits of eleven brains investigated so far. The cells of the limbic system (hippocampus, amygdala, mamillary bodies, cingulate gyrus and septal nuclei) are small in size, but large in number per unit of volume (increased cell density) compared to controls. This led to the hypothesis of a delay in the maturational development of limbic system circuits. The investigated cerebellums revealed a low number of Purkinje cells, especially in the posterolateral neocerebellum and in the adjacent archicerebellar cortex (posterior and inferior portions of the cerebellum). The inferior olivary nucleus in the investigated brains did not show expected retrograde neuronal loss (secondary to the loss of Purkinje cells). This suggests that abnormal findings in the brains of autistic individuals occurred at around 30 weeks' gestation, before the connection between the olive and Purkinje cells was established.

Recent studies suggest that minicolumnar organization of the brain is abnormal in autistic individuals. Minicolumns are very thin radial structures $(30-60 \mu)$ that represent the lowest level of vertical cortical organization. In autistic individuals, a larger number of minicolumns, smaller and less compact than expected, has been described. These findings suggest that abnormalities in the proliferation of neuronal precursor cells or changes in the minicolumnar architecture due to diverse causes may be related to the neuropathology of autism and of other developmental disorders. $29-31$

Neuroimaging studies in autistic individuals yielded different results as expected, given the clinical heterogeneity of ASD. Cortical abnormalities include enlarged volume of left lateral ventricle or of both ventricles, cortical malformations such as polymicrogyria, schizencephaly and macrogyria. ${ }^{30-33}$ None of these findings is consistent with or specific to autism. Abnormal findings in the posterior fossa structures described in autistic patients include hypoplasia of lobules VI and VII of the cerebellar vermis and brainstem hypoplasia. 34-36 Abnormal cerebellar findings were not properly reproduced and some researchers believe they may be related to technical and methodological factors. 37,38 Courchesne et al. performed a meta-analysis including data from various laboratories and suggested a bimodal distribution of the measures of cerebellar vermis in investigated autistic patients. They found two subgroups, one with hypoplasia and another one with hyperplasia of lobules VI and VII of the vermis. Over $80 \%$ of the patients belonged to the group with hypoplasia. Besides inter-group differences, both groups were significantly different from controls. 39,40

There is some clear discrepancy between neuropathological and neuroimaging studies in autism.
Neuropathological studies showed that the most remarkable anatomical abnormalities are observed in the posterior and inferior portions of cerebellar hemispheres and involve cell loss. This cell loss has been observed throughout the cerebellum, affecting the vermis evenly. However, neuroimaging studies showed that volume loss was concentrated on lobules VI and VII. Therefore, the vermis may become the best in vivo indicative sign that cerebellum as a whole is abnormal in autistic individuals, and this emphasis of neuroimaging studies on lobules I-IV and VI-VII may simply represent the ease and reliability with which these structures can be measured. ${ }^{41}$ Other studies used the above data to show that the level of hypoplasia may correlate with slower attention responses to visual stimuli, when a spatial paradigm of attention is used, in children with cerebellar hypoplasia and autism. This is consistent with the literature that suggests that cerebellum plays a key role in autism and in an array of other disorders that involve higher cognitive functions. ${ }^{42}$

Recent data show that memory deficits, and procedural learning deficits are important in autism and could be related to cerebellar dysfunction. 43

Several morphometric analyses using magnetic resonance have been published, showing the relation between head circumference, brain volume, and autism. 44,45

The head size in autistic individuals tends to be similar to that of healthy children at birth. 50,51 Nevertheless, between the ages of two and four years, $90 \%$ of autistic children have a brain volume that is larger than the average for same-aged children, and $37 \%$ have macrocephaly. 46

Neuroimaging studies suggest an abnormal brain development pattern in autistic patients, with an accelerated growth in the first years of life followed by deceleration in some brain regions, whereas growth arrest is noted in other areas.

A study with a group of autistic individuals aged between 8 and 46 years, compared with a control group, revealed increased brain volume in autistic children aged from 8 to 12 years, but no increase in those older than 12 years. ${ }^{47}$ Courchesne et al. reported that $90 \%$ of autistic boys aged between two and four years had a larger volume of cerebral and cerebellar white matter and of gray matter compared to controls, but this was not observed among older autistic children. 48 Larger brain volume in very young autistic children seems to follow an anteroposterior gradient: frontal lobes show a larger volume, while occipital lobes have a smaller increase in volume. 49,50

Recent studies have used functional magnetic resonance (fMRI) to investigate areas of social processing in autism. Usually, during fMRI, there is a marked activation of the fusiform gyrus (facial fusiform area) in response to pictures of faces, which is remarkably 
reduced in autistic individuals, who tend to activate other regions (frontal, occipital). Hypoactivation of the facial fusiform area is not reliant on age or IQ, but seems to be related to the level of social deficit and may be used as a biological marker that could be replicated in autistic patients. This area of research on autism reinforces the idea of a social circuit involving the fusiform gyrus (recognition of faces), amygdala (meaning assignment/emotional "value" of what is seen), superior and medial temporal gyri (distinction of facial expressions), as well as mesial prefrontal cortex, hypothalamus and pulvinar. ${ }^{51-54}$

\section{Neurochemistry}

The elevation of serotonin levels in platelets is the most consistent finding in autistic patients. It has been suggested that the elevation of serotonin levels in autistic patients may be heterogeneous, with a subgroup where there is an increase in 5-HT uptake and another subgroup with a decrease in $5-\mathrm{HT} 2$ receptor binding. 55 Only recently, possible relations between serotonin, neurodevelopment and autism have been explored. A too early serotonin depletion in rat fetuses leads to permanent reduction in the number of neurons in adult rats. ${ }^{56}$ On the other hand, persistently high levels of serotonin could indicate a deficit in synaptic release in brains of autistic individuals and may contribute to the increase in the number of cortical minicolumns. 57

Chugani et al. reported a series of studies using PET scan with alpha-methyl-tryptophan. A study showed abnormal serotonin synthesis in dentate-thalamo-cortical tracts of male autistic individuals. 58 Moreover, the period of elevated serotonin synthesis in the brain of typical children up to the age of five years (synthesis capacity $200 \%$ greater than in adults) does not seem to occur in autistic children. In the latter, the capacity of serotonin synthesis gradually increases between the ages of two and 11 years, resulting in values that are 1.5 times greater than those observed in typical adults. 59,60

\section{Electrophysiology}

Abnormal EEGs are obtained in $13 \%$ to $83 \%$ of autistic children. ${ }^{61}$ The varying percentage rates between these studies may probably be explained by the different criteria used for the clinical diagnosis of autism, by associated diseases, and by different evaluation methods and distinct ways of interpreting results. Long EEG recordings are significantly more likely to identify abnormal findings than routine exams, at least in children with ASD and with a history of regression. Twentythree-hour Video-EEGs, in children with ASD and regression, but without a history of seizures, showed epileptiform activities in $46 \%$ of these children. 62,63

Magnetoelectroencephalography in children with ASD and regression (and suspected of having seizures) revealed epileptiform activity in $82 \%$ of investigated children. ${ }^{64}$ The high incidence of seizures and epileptiform activities in children with ASD is particularly interesting owing to findings about the role of amygdala in autism, since it is a highly epileptogenic region.

Studies including auditory evoked potentials or middlelatency auditory-evoked response did not show consistent findings in autistic patients without mental retardation. 65 Klin ${ }^{66}$ reviewed the literature on ASD and autism and found quite contradictory results, with some studies showing prolongation, others showing reduction and some showing no abnormality in central conduction latency. Hearing problems may coexist with autism and this has to be taken into account clinically and in evoked potential studies. ${ }^{67}$ Abnormal findings in endogenous or event-related potentials have been reported and suggest abnormal cortical processing. 68,69

\section{Genetics}

Genetic studies have demonstrated an increased risk of autism recurrence of approximately $3 \%$ to $8 \%$ in families with one autistic child. 75,76 The concordance for the diagnosis of autism in monozygous twins is of at least $60 \%$, if strict criteria for autism (DSM-IV) are used, and of $71 \%$ for ASD and of $92 \%$ for a broader spectrum of language/social interaction disorders. ${ }^{70,71}$

Whole genome analysis has revealed strongly positive signs of correlation on chromosomes 2, 7, 1 and 17, especially on $2 \mathrm{q}$ and $7 \mathrm{q}$, and to a lesser extent, on chromosomes 1, 9, 13,15, 19, 22 and X. ${ }^{72-74}$ The "link" between chromosomes 2 and 7 and autism is particularly robust when only autistic patients with severe language disabilities are studied.

The International Molecular Genetic Study of Autism Consortium, in 1998, found evidence of susceptibility on the long arm of chromosome 7 (7q31), in a region previously associated with a severe familial language disability, but only in the subgroup of 56 families from the United Kingdom. ${ }^{75}$ Other studies found little evidence of this susceptibility. ${ }^{77,78}$ The gene responsible for this severe language disorder was identified as a putative transcription factor (FOXP2). ${ }^{79}$ Another gene located on chromosome 7 with possible association with autism and the gene that encodes reelin (RELN). This extracellular protein guides neuronal migration during brain development, especially of the cerebral cortex, cerebellum, hippocampus and brainstem. 80,81

Ingram et al. showed that there is statistical significance in the frequency of allelic variations of HOXA1 in a population of autistic patients comparatively to two groups of non-autistic patients. ${ }^{82}$ HOXA1 and HOXB1 are critical for the development of caudal medullary structures of the fetus and are only expressed on the third week after conception, when the neural tube is being formed, and seem to be particularly involved in 
the formation of the superior olivary nucleus and of the facial and abducens nuclei. This study suggests a role for HOXA1 in the susceptibility for autism and implies a relation between the earliest phase of brainstem development in the etiology of ASD. Despite the great interest aroused by original studies, the data on a possible association between autism, reelin and HOXA1 have been inconsistent. ${ }^{83-85}$

Several studies have described a possible association between autism and cytogenetic duplications of the proximal arm of chromosome $15 .{ }^{86-90}$ In this region, we also have the deletions responsible for Prader-Willi and Angelman's syndromes. A high association between autism and Angelman's syndrome ${ }^{91}$ has been reported. However, none of the autistic children with inverse duplication of 15q11-q13 had clinical characteristics of Angelman's or Prader-Willi syndromes. An association has been described with 15q11-q13 in a large group of autistic individuals ${ }^{92}$ and genetic polymorphism involving chromosome 15, with a marker in a GABAa receptor subunit. 93 Nevertheless, among four collaborative studies, only the French study confirmed this finding.

A relation between preferential transmission of alleles of genetic markers of two serotonin transporter genes and autism has been suggested. ${ }^{94}$ These findings, however, were not replicated in a later study. ${ }^{95}$

The relation between genetic factors in the expression of an autism spectrum disorder and the role of nongenetic events in determining the severity of these disorders needs to be further investigated. ${ }^{96}$ Autism is a complex genetic disorder and, based on low scores obtained from genome collaborative studies, it has been suggested that approximately 5 to 100 loci may be involved in the susceptibility for ASD. Although multiple chromosomes have been implicated in autism, no definitive answer has been found.97-99

\section{Therapeutic interventions}

The treatment of autistic patients requires a multidisciplinary approach. Basic treatment consists of behavioral changes, educational or work programs, and speech therapy. It is crucial to work with psychologists or educators who are experienced in functional behavioral analysis and in behavioral change techniques. In addition to social and cognitive deficits, behavioral disorders are of enormous concern since they represent the difficulties that most frequently interfere with children's integration into their families and school, and with adolescents' and adults' integration into the community. In children, these disorders include hyperactivity, inattention, aggressiveness, and self-injurious behaviors. Behavioral disorders persist in a significant number of adolescents and adults and aggressiveness and self-injurious behaviors may increase during adolescence. Abnormal responses to sensory stimuli, such as loud sounds, tactile hypersensitivity, fascination with some visual stimuli and high tolerance of pain, also contribute to behavioral disorders in autistic patients. Mood and affective disorders are common. These disorders may be characterized by laughing or crying fits for no apparent reason, unawareness of danger or, excessive fear, generalized anxiety, fits of anger, self-injurious behavior or absent or reduced emotional reactions. 100

Abnormal movements are common in autistic individuals and include stereotypies (repeated hand movements, repetitive swinging of the body or complex body movements), as well as abnormal posture and a wide variety of other involuntary movements. 101 Stereotypies persist in a significant number of autistic adults (even in high-functioning ones), but sometimes become "miniaturized."102.

In adolescents and adults, the possibility that abnormal movements may result from the use of neuroleptics should be considered. A study showed that typical stereotypies observed in autistic patients cannot be certainly distinguished from dyskinesis. ${ }^{103}$ This finding draws attention to the importance of characterizing and quantifying abnormal movements before prescribing medications.

Seizures occur in $16 \%$ to $35 \%$ of autistic children. The variation in prevalence is due to the differences between the studied populations as to associated diseases. The major risk factors for epilepsy are severe mental retardation and combination of severe mental retardation with motor deficit (in this case, $40 \%$ of the children had epilepsy). ${ }^{104}$ If cognitive and motor deficits are ruled out, the only factor associated with an increased risk for epilepsy in autistic children is the type of language disability. Any type of seizure may occur in autistic children. The association between autism and infantile spasm (West syndrome) is an interesting finding. Various studies have suggested a bimodal distribution of the risk of epilepsy in autistic children: a peak incidence in the first year of life and another one in adolescence. 105-107 This second peak in adolescence, which reaches its maximum between the ages of 17 and 18 years, gradually decreases after this age and seems to be associated with the severity of cognitive deficit. 108 The management of seizures in autistic patients is not different from that used in non-autistic individuals, but the risk of seizures should be considered when selecting the drugs to treat behavioral disorders.

A considerable number of autistic patients have sleeprelated problems, but there is a paucity of studies on sleep disorders in autistic individuals. A recent study with nonautistic children who suffer from other developmental disorders suggested a narrow and quantifiable relationship between changes in sleep architecture and the results of neuropsychological tests that evaluate attention, concentration, psychomotor speed, and higher cognitive functions. ${ }^{109}$ The association between sleep disorders and behavioral and cognitive symptoms of autism needs to be further investigated. 


\section{Pharmacotherapy}

The use of drugs to treat autism is still recent. Neuroleptics, especially haloperidol, have been widely used to treat behavioral disorders in autistic patients. However, possible side effects restrict their use in chronic disorders, such as autism. Haloperidol has proved to remarkably reduce aggressiveness, stereotypies and selfinjurious behaviors in autistic individuals. ${ }^{110-112}$ Atypical antipsychotics seem to have positive effects on target symptoms, such as irritability, aggressiveness, and hyperactivity in ASD patients. In a controlled multicenter study, which was regarded as a pioneering study due to the number of autistic patients (101) and to the selection of well-defined target symptoms, a group specifically formed to investigate the use of psychotropic drugs in pediatrics (Research Unit in Pediatric Psychopharmacology or RUPP), showed a clear improvement in aggressiveness and irritability in patients treated with risperidone $(0.5$ to $3.5 \mathrm{mg} /$ day). The number of stereotypies also decreased significantly. ${ }^{113}$ Side effects, sedation and weight gain were relatively mild. Unpublished data with a four-month follow-up, including patients that responded to risperidone and those who did not respond to placebo, suggest that medication was maintained during this time period.

Uncontrolled studies with quite a small number of patients using olanzapine, quetiapine and ziprasidone suggest that these atypical antipsychotics might have similar effects to that of risperidone. ${ }^{114-116}$ Possibly significant side effects, such as elevation of prolactin and triglyceride (risperidone, quetiapine and olanzapine) levels, a greater risk for type 2 diabetes (olanzapine and possibly other atypical antipsychotics), and long QT syndrome (ziprasidone) require that these patients be carefully monitored. ${ }^{117-119}$

Clomipramine (tricyclic antidepressant and nonselective serotonin reuptake blocker) proved to be efficient in the treatment of obsessive-compulsive behavior and, more recently, in obsessive-compulsive symptoms, in the minimization of stereotypies and self-injurious behavior in autistic patients. The risk of cardiac arrhythmias, among others, has restricted its use. 120,121

Selective serotonin reuptake inhibitors, such as fluoxetine, fluvoxamine, paroxetine, sertraline and citalopram have been used in autistic individuals in an attempt to reduce obsessive behaviors, rituals and stereotypies with variable efficacy, being usually well tolerated. 122 Two controlled studies with adult autistic patients (one with fluoxetine and one with fluvoxamine) showed improvement of repetitive behaviors, compared to placebo. ${ }^{123}$ Akathisia or "excessive activation" seems to be a relatively frequent dose-dependent side effect.

Drugs with glutamate modulating effects have been considered for autistic patients. A controlled study using amantidine in 39 autistic patients between 5 and 15 years suggests a positive effect on irritability and hyperactivity, but the sample size might have been extremely small. ${ }^{124}$ Lamotrigine, even at high serum levels, did not show significant differences comparatively to placebo. 125

No data are available that support the use of naltrexone to reduce self-injurious behaviors.

Buspirone, $5 \mathrm{HT}$ receptor agonist, may have a positive effect by reducing anxiety and, in a second moment, reducing stereotyped or self-injurious behaviors. 126

Clonidine seems to be useful in the treatment of hyperactivity, impulsivity, and aggressive behavior, although very few studies have been conducted to confirm this clinical impression. 127

It has been reported that pyridoxine (vitamin B6) and magnesium may increase the state of alertness and minimize self-injurious behaviors. Most of these studies had methodological problems and their results have not been confirmed by controlled studies. ${ }^{128,129}$

In 1998, Horvath et al. ${ }^{130}$ described "improvement of social and language skills" after the intravenous administration of secretin (a peptide hormone with 27 amino acids) in three autistic patients with gastrointestinal symptoms (secretin is used as part of an endoscopic diagnostic test). Since then, a large number of autistic children have received this "treatment." Subsequently, thirteen controlled and randomized studies were carried out with more than 550 patients. Eleven of these studies ( \pm 520 patients) did not show significant differences between secretin-treated patients and the control group as to basic symptoms of autism or to abnormal behavior.

Children with autism spectrum disorders, speech regression (auditory verbal agnosia) and abnormal epileptiform activities on EEG, with no history of seizures, have been described as having autistic epileptiform regression (AER). Treatments such as those used in patients with Landau-Kleffner syndrome were tested in a limited number of studies with children in this ASD subgroup. Four of these studies described cases in which valproic acid was used in children with ASD without history of seizures, but with epileptiform activities on EEG. ${ }^{131,132}$ Another study describes the use of steroids in an autistic child with auditory verbal agnosia and regression, but with normal EEG findings. ${ }^{133}$ In the literature, there are many abstracts and case reports about the use of valproic acid and steroids in children with AER, but controlled studies are still necessary. A small number of studies in children with autistic regression and epilepsy (clinical history of seizures) has suggested the possible use of epilepsy surgery techniques with positive results. ${ }^{134,135}$ In these cases, children suffered from intractable epilepsy and this was the indication for surgical treatment. In a postoperative study, there was improved seizure control but no improvement in autistic symptoms. ${ }^{136}$ On the other hand, Lewine et al. ${ }^{137}$ described improvement in behavior and language in 12 out of 18 children with ASD, speech regression, abnormal multifocal epileptiform activities and possible subclinical seizures (blank stare, repetitive blinking, etc), but with no clinical history of seizures after 
multiple subpial transections. The results of this study are controversial and show the necessity of controlled studies in order to avoid inappropriate and irreversible interventions. If we consider that the indication of surgical treatment to treat behavioral symptoms in children with Landau-Kleffner syndrome is still controversial and has to be validated, ${ }^{138}$ its use in children with ASD is currently unacceptable.

\section{Prognosis}

In 1978 , Lotter $^{139}$ reviewed articles on autism until the mid-1970s. Eight studies from the United Kingdom, three from the USA, and one from Belgium were analyzed. The conclusion of these studies is that the prognosis of autism is variable and often tends to be poor, with $66 \%$ of individuals suffering from severe disabilities with no social improvement or unable to lead an independent life. Gillberg \& Steffenburg ${ }^{140}$ obtained similar results in a population-based study. In general, the prognosis of autism is variable and probably relies on the severity of underlying etiologies. ${ }^{105}$ Studies that have followed autistic children up to adulthood revealed that the prognosis is related to their skills, which is shown in cognitive and language tests. Approximately 5 to $10 \%$ of the studied children became independent adults ( $1 \%$ to $2 \%$ with normal cognitive and language tests) and around $25 \%$ made a considerable progress, showing some degree of independence. The remaining $65 \%$ to $70 \%$ still have quite significant deficits and require extensive care. ${ }^{141,142} \mathrm{~A}$ study performed in Japan ${ }^{143}$ suggested that the prognosis of individuals with autism could be improving: 54 of 197 $(27.4 \%)$ autistic adults had attained a reasonable social improvement (they were employed and living independently or almost independently). The reasons for this better result included the fact that these individuals received early and intensive intervention; that this study included high-functioning individuals; and that the good economic situation of Japan favored jog openings.

Early intervention programs can make an enormous difference and result in significant and long-lasting gains. It is reasonable to suppose that individuals with autism and other associated diseases, such as tuberous sclerosis, will have a different prognosis from those without severe disorders associated, but this has not been clearly demonstrated. It is common knowledge that better and more widely available educational and community services will be able to change the long-term prognosis of autistic patients. 143,144

Autism is a complex disorder that affects social and cognitive development and as such gives us the opportunity to understand and identify the neuronal systems that determine social interaction and communication. The spectrum of clinical presentation and symptoms suggests neurobiological heterogeneity. The identification of specific subgroups of individuals within the autism spectrum is essential for improved understanding of its neurobiological bases. Cooperation between neurologists, psychiatrists, neuroscientists, psychologists, speech therapists, occupational therapists and educators is crucial for the elucidation of autism spectrum disorders, for a more appropriate management of patients, and for a clearer view of social being as a whole.

\section{References}

1. Ajuriahuerra J. Las Psicosis Infantiles. In Manual de Psiquiatría Infantil. 4th ed. Barcelona: Toray-Masson; 1977. p. 673-731.

2. Kanner L. Autistic disturbances of affective contact. Nervous Child. 1943;2:217-50.

3. Rutter M, Schopler E. Classification of pervasive developmental disorders: some concepts and practical considerations. J Autism Dev Disord. 1992;22:459-82.

4. Minshew NJ, Payton JB. New perspectives in autism, Part I: the clinical spectrum of autism. Curr Probl Pediatr. 1988;18:561-610.

5. Minshew NJ, Payton JB. New perspectives in autism, Part II: the differential diagnosis and neurobiology of autism. Curr Probl Pediatr. 1988;18:613-94.

6. Rapin I. Disorders of higher cerebral function in preschool children. Part I. AJDC. 1988;142:1119-24.

7. Rapin I. Disorders of higher cerebral function in preschool children. Part II. AJDC. 1988;142:1178-82.

8. Tuchman R, Rapin I, Shinnar S. Autistic and dysphasic children: I Clinical characteristics. Pediatrics. 1991;88:1211-18.

9. Schopler E. Convergence of learning disability, higher level autism and Asperger's syndrome. J Autism Dev Disord. 1985;15:359-60.

10. DSM-IV. Pervasive Developmental Disorders. In: Diagnostic and Statistical Manual of Mental Disorders. 4th ed. Washington, DC: American Psychiatric Association; 1994. p. 65-78.

11. Rapin I. Autistic children: diagnosis and clinical features. Pediatrics. 1991;87:751-60.

12. Gillberg C, Coleman M. Prevalence of autism and autistic-like conditions. The Biology of the Autistic Syndromes. New York: Mac Keith Press; 1992. p. 85-95.

13. Fombonne E. Epidemiological trends in rates of autism. Mol Psychiatry. 2002;7 Suppl 2:4.

14. Wing $L$, Potter $D$. The epidemiology of autistic spectrum disorders: is the prevalence rising? Ment Retard Dev Disabil Res Rev. 2002;8:151.

15. Kurtzke J. Neuroepidemiology. In: Bradley W, Daroff R, Fenichel G, Marsden C, editors. Neurology in Clinical Practice. Stoneham: Butterworth-Heinemann; 1991. p. 545-560.

16. Cohen DJ, Volkmar F, Anderson G, Klin A. Integrating biological and behavioral perspectives in the study and care of autistic individuals: the future. Isr J Psychiatry Relat Sci. 1993;30:15-32.

17. Rutter M, Schopler E. Classification of pervasive developmental disorders: some concepts and practical considerations. J Autism Dev Disord. 1992;22:459-82.

18. Percy A. Genetics of Rett syndrome: properties of the newly discovered gene and pathobiology of the disorder. Curr Opin Pediatr. 2000;12:589-95.

19. Wiznitzer M. Autism and Tuberous Sclerosis. 3rd Neurobiology of Disease in Children Symposium. 32 ${ }^{\text {nd }}$ Annual Child Neurology Society Meeting, Miami, 2003.

20. Gillberg C, Coleman M. Theoretical considerations: CNS mechanisms underlying the autistic syndromes. In: The Biology of the Autistic Syndromes. New York: Mackeith Press; 1992. p. 283-295.

21. Schopler E, Reichler R, Renner B. Childhood Autism Rating Scale (CARS). Los Angeles: Western Psychological Services; 1986.

22. Volkmar FR, Carter A, Sparrow SS, Cicchetti DV. Quantifying social development in autism. J Am Acad Child Adolesc Psychiatry. $1993 ; 32: 627-32$

23. LeCouteur A, Rutter M, Lord C, Rios P, Robertson S, Holdgrafer $M$, et al. Autism diagnostic interview: a standardized investigatorbased instrument. J Aut Dev Dis. 1989;19:363-87.

24. Lord C. Methods and measures of behavior in the diagnosis of autism and related disorders. Psychiatr Clin North Am. 1991; 14:69-80. 
25. Lord C, Pickles A, McLennan J, Rutter M, Bregman J, Folstein S, et al. Diagnosing autism: analyses of data from the Autism Diagnostic Interview. J Autism Dev Disord. 1997;27:501-17.

26. Robertson JM, Tanguay PE, L'Ecuyer S, Sims A, Waltrip C. Domains of social communication handicap in autism spectrum disorder. J Am Acad Child Adolesc Psychiatry. 1999;38:738-45.

27. Bauman M. Microscopic neuroanatomic abnormalities in autism. Pediatrics. 1991;87 Suppl 5:791-5.

28. Casanova M, Buxhoeveden D, Brown C. Clinical and macroscopic correlates of minicolumnar pathology in autism. J Child Neurol. 2002;17:692.

29. Casanova MF, Buxhoeveden DP, Switala AE, Roy E. Minicolumnar pathology in autism. Neurology. 2002;58:428-32.

30. Courchesne E. Neuroanatomic imaging in autism. Pediatrics. 1991;87:781-90.

31. Berthier ML, Bayes A, Tolosa ES. Magnetic resonance imaging in patients with concurrent Tourette's disorder and Asperger's syndrome. J Am Acad Child Adolesc Psychiatry. 1993;32:633-9.

32. Piven J, Berhier M, Starkstein S, Nehme E, Pearlson G, Folstein S. Magnetic resonance imaging evidence for a defect of cerebral cortical development in autism. Am J Psychiatry. 1990;147: 734-9.

33. Nowell M, Hackney D, Muraki A, Coleman M. Varied MR appearance of autism: Fifty-three pediatric patients having the full autistic syndrome. Magn Reson Imaging. 1990;8:811-16.

34. Courchesne E, Yeung-Courchesne BA, Press GA, Hesselink JR, Jernigan TL. Hypoplasia of cerebellar vermal lobules VI and VII in autism. N Engl J Med. 1988;318:1349-54.

35. Kleiman MD, Neff S, Rosman NP. The brain in infantile autism: are posterior fossa structures abnormal? Neurology. 1992;42:753-60.

36. Hashimoto T, Tayama M, Miyazaki M, Murakawa K, Kuroda Y. Brainstem and cerebellar vermis involvement in autistic children. J Child Neurol. 1993;8:149-53.

37. Holttum JR, Minshew NJ, Sanders RS, Phillips NE. Magnetic resonance imaging of the posterior fossa in autism. Biol Psychiatry. 1992;32:1091-101.

38. Courchesne E, Saitoh O, Yeung-Courchesne R, Press GA, Lincoln AJ, Haas RH, et al. Abnormality of cerebellar vermian lobules VI and VII in patients with infantile autism: identification of hypoplastic and hyperplastic subgroups with MR imaging. Ajr Am J Roentgenol. 1994;162:123-30.

39. Courchesne E. New evidence of cerebellar and brainstem hypoplasia in autistic infants, children and adolescents: the MR imaging study by Hashimoto and colleagues. J Autism Dev Disord. $1995 ; 25: 19-22$.

40. Filipek PA. Quantitative magnetic resonance imaging in autism: the cerebellar vermis. Curr Opin Neurol. 1995;8:134-8.

41. Harris NS, Courchesne E, Townsend J, Carper RA, Lord C. Neuroanatomic contributions to slowed orienting of attention in children with autism. Brain Res Cogn Brain Res. 1999;8:61-71.

42. Schmahmann J. The cerebellum in autism: clinical and anatomic perspectives. In: Bauman M, Kemper T, editors. The neurobiology of autism. Baltimore: John Hopkins University Press; 1994. p. 195-226.

43. Mostofsky SH, Goldberg MC, Landa RJ, Denckla MB. Evidence for a deficit in procedural learning in children and adolescents with autism: implications for cerebellar contribution. J. Int Neuropsychol Soc. 2000;6:752-9.

44. Fidler D, Bailey J, Smalley S. Macrocephaly in autism and other pervasive developmental disorders. Dev Med Child Neurol. 2000;42:737-40

45. Fombonne E, Roge B, Claverie J, Courty S, Fremolle J. Microcephaly and macrocephaly in autism. J Autism Dev Disord. 1999;29:113-9.

46. Lainhart JE, Piven J, Wzorek M, Landa R, Santangelo SL, Coon $\mathrm{H}$, et al. Macrocephaly in children and adults with autism. J Am Acad Child Adolesc Psychiatry. 1997;36:282-90.

47. Aylward EH, Minshew NJ, Field K, Sparks BF, Singh N. Effects of age on brain volume and head circumference in autism. Neurology. 2002;59:351-4.

48. Courchesne E, Karns CM, Davis HR, Ziccardi R, Carper RA, Tigue ZD, et al. Unusual brain growth patterns in early life in patients with autistic disorder: an MRI study. Neurology. 2001;57:245-54.

49. Carper $R$, Courchesne E. Inverse correlation between frontal lobe and cerebellum sizes in children with autism. Brain. 2000;123:836-44.

50. Carper R, Moses P, Tigue Z, Courchesne E. Cerebral lobes in autism: early hyperplasia and abnormal age effects. Neuroimage. $2002 ; 16: 1038$.
51. Klin A, Lones W, Schultz R, Volkmar F, Cohen D. Visual fixation patterns during viewing of naturalistic social situations as predictors of social competence in individuals with autism. Arch Gen Psychiatry. 2002;59:809-16.

52. Schultz R, Gauthier I, Klin A, Fulbright R, Anderson A, Volkmar $F$, et al. Abnormal ventral temporal cortical activity during face discrimination among individuals with autism and Asperger syndrome. Arch Gen Psychiatry. 2000;57:331-40.

53. Schultz R, Grelotti D, Klin A, Kleinman J, van der Gaag C, Marols $R$, et al. The role of the fusiform face area in social cognition: implications for the pathobiology of autism. Philos Trans R Soc Lond B Biol Sci. 2003;358:415-27.

54. Pierce K, Muller R, Ambrose J, Allen G, Courchesne E. Face processing occurs outside the fusiform "face area" in autism: evidence from functional MRI. Brain. 2001;124:2059-73.

55. Anderson G. Genetics of childhood disorders: XLV. Autism, part 4: serotonin in autism. J Am Acad Child Adolesc Psychiatry. 2002;41:1513.

56. Whitaker-Azmitia P. Serotonin and brain development: role in human developmental diseases. Brain Res Bull. 2001;56:479-85.

57. Keller F, Persico A. The neurobiological context of autism. Mol Neurobiol. 2003;28:1-22.

58. Chugani DC, Muzik O, Behen M, Rothermel R, Janisse JJ, Lee J, et al. Developmental changes in brain serotonin synthesis capacity in autistic and nonautistic children. Ann Neurol. 1999;45:287-95.

59. Muller RA, Chugani DC, Behen ME, Rothermel RD, Muzik O, Chakraborty PK, et al. Impairment of dentato-thalamo-cortical pathway in autistic men: language activation data from positron emission tomography. Neurosci Lett. 1998;245:1-4.

60. Chugani DC, Muzik O, Rothermel R, Behen M, Chakraborty P, Mangner $T$, et al. Altered serotonin synthesis in the dentatothalamocortical pathway in autistic boys. Ann Neurol. 1997;42:666-9.

61. Chugani DC. Role of altered brain serotonin mechanisms in autism. Mol Psychiatry. 2002;7 Suppl 2:16-7.

62. Tuchman R, Rapin I. Regression in pervasive developmental disorders: seizures and epileptiform electroencephalogram correlates. Pediatrics. 1997;99:560.

63. Tuchman R, Jayakar P, Yaylali I, Villalobos R. Seizures and EEG findings in children with autism spectrum disorders. CNS Spectrums. 1997;3:61-70.

64. Lewine JD, Andrews R, Chez M, Patil AA, Devinsky O, Smith M, et al. Magnetoencephalographic patterns of epileptiform activity in children with regressive autism spectrum disorders. Pediatrics. 1999; 104:405-18.

65. Grillon C, Courchesne E, Akshoomoff N. Brainstem and middle latency auditory evoked potentials in autism and developmental language disorder. J Autism Dev Dis. 1989;19:255-69.

66. Klin A. Auditory brainstem responses in autism: brainstem dysfunction or peripheral hearing loss? J Autism Dev Disord. 1993;23:15-35.

67. Jure R, Rapin I, Tuchman RF. Hearing-impaired autistic children. Dev Med Child Neurol. 1991;33:1062-72.

68. Lincoln AJ, Courchesne E, Harms L, Allen M. Contextual probability evaluation in autistic, receptive developmental language disorder, and control children: event-related brain potential evidence. J Autism Dev Disord. 1993;23:37-58.

69. Lotspeich LJ, Ciaranello RD. The neurobiology and genetics of infantile autism. Int Rev Neurobiol. 1993;35:87-129.

70. Folstein S, Piven J. Etiology of autism: genetic influences. Pediatrics. 1991;87:767-73.

71. Folstein S, Rutter M. Infantile autism: a genetic study of 21 twin pairs. J Child Psychol Psychiatry. 1977;18:29-321.

72. Bailey A, Le Couteur A, Gottesman I, Bolton P, Simonoff E, Yuzda $\mathrm{E}$, et al. Autism as a strongly genetic disorder: evidence from a British twin study. Psychol Med. 1995;25:63-77.

73. Petit E, Herault J, Martineau J, Perrot A, Barthelemy C, Hameury $L$, et al. Association study with two markers of a human homeogene in infantile autism. J Med Genet. 1995;32:269-74.

74. Gutknecht I. Full-genome scans with autistic disorders: a review. Behav Genet. 2001;31:113-23.

75. Shao Y, Wolpert CM, Raiford KL, Menold MM, Donnelly SL, Ravan $\mathrm{SA}$, et al. Genomic screen and follow-up analysis for autistic disorders. Am J Med Genet. 2002;114:99-105.

76. Fisher S, Vargha-Kadem F, Watkins K, Monaco A, Pembrey M. Localization of a gene implicated in a severe speech and language disorder. Nat Genetics. 1998;18:16-170 
77. Philippe A, Martinez M, Guilloud-Bataille M, Gillberg C, Rastam M, Sponheim E, et al. Genome-wide scan for autism susceptibility genes. Paris Autism Research International Sibpair Study. Hum Mol Genet. 1999;8:805-12.

78. Risch N, Spiker D, Lotspeich L, Nouri N, Hinds D, Hallmayer J, et al. A genomic screen of autism: evidence for a multilocus etiology. Am J Hum Genet. 1999;65:493-507.

79. Collaborative Linkage Study of Autism. An autosomal genomic screen for autism. Am J Med Genet. 1999;88:600-15.

80. Lai CS, Fisher SE, Hurst JA, Vargha-Khadem F, Monaco AP. A fork-head domain gene is mutated in a severe speech and language disorder. Nature. 2001;413:519-23.

81. Persico AM, D’Agruma L, Maiorano N, Totaro A, Militerni R, Bravaccio $C$, et al. Reelin gene alleles and haplotypes as a factor predisposing to autistic disorder. Mol Psychiatry. 2001;6:150-9.

82. Fatemi S, Stary J, Halt A, Realmutto G. Dysregulation of reelin and Rel-2 proteins in autistic cerebellum. J Autism Dev Disord. 2001;31:529-35.

83. Ingram J, Stodgell C, Hyman S, Figlewics D, Weitkamp L, Rodier P. Discovery of allelic variants of HOXA1 and HOXB1: genetic susceptibility to autism spectrum disorders. Teratology. $2000 ; 62: 393-405$.

84. Krebs MO, Betancur C, Leroy S, Bourdel MC, Gillberg C, Leboyer $M$, et al. Absence of association between a polymorphic GGC repeat in the $5^{\prime}$ untranslated region of the reelin gene and autism. Mol Psychiatry. 2002;7:801-4.

85. Li J, Tabor HK, Nguyen L, Gleason C, Lotspeich LJ, Spiker D, et al. Lack of association between HoxA1 amd HoxB1 gene variants and autism in 110 multiplex families. Am J Med Genet. 2002;114:24-30.

86. Talebizadeh Z, Bittel DC, Miles JH, Takahashi N, Wang $\mathrm{CH}$, Kibiryeva N, et al. No association between HOXA1 and HOXAB1 genes and autistic spectrum disorders (ASD). J Med Genet. 2002;39:e70.

87. Baker P, Piven J, Schwartz S, Patil S. Brief report: duplication of chromosome $15 q 11-13$ in two individuals with autistic disorder. Autism Dev Disord. 1994;24:529-35.

88. Bundey S, Hardy C, Vickers S, Kilpatrick MW, Corbett JA. Duplication of the $15 q 11-13$ region in a patient with autism, epilepsy and ataxia. Dev Med Child Neurol. 1994;36:736-42.

89. Flejter WL, Bennett-Baker PE, Ghaziuddin M, McDonald M, Sheldon S, Gorski JL. Cytogenetic and molecular analysis of inv dup(15) chromosomes observed in two patients with autistic disorder and mental retardation. Am J Med Genet. 1996;61: 182-7.

90. Gillberg C, Steffenburg S, Wahlstrom J, Gillberg IC, Sjostedt A, Martinsson T, et al. Autism associated with marker chromosome. J Am Acad Child Adolesc Psychiatry. 1991;30:489-94.

91. Hotopf M, Bolton P. A case of autism associated with partial tetrasomy 15. J Autism Dev Disord. 1995;25:41-9.

92. Steffenburg S, Gillberg CL, Steffenburg U, Kyllerman M. Autism in Angelman Syndrome: a population based study. Pediatr Neurol. 1996;14:131-6.

93. Pericak-Vance MA, Wolpert CM, Menold MM, Bass MP, DeLong GR, Beaty LM, Zimmerman A, et al. Linkage evidence supports the involvement of chromosome 15 in autistic disorder. Am J Hum Genet. 1997;61(4):A40.

94. Cook EH Jr, Courchesne RY, Cox NJ, Lord C, Gonen D, Guter SJ, et al. Linkage disequilibrium mapping with $15 q-13$ markers in autistic disorder. Am J Hum Genet. 1998;62:1077-83.

95. Cook EH Jr, Courchesne R, Lord C, Cox NJ, Yan S, Lincoln A, et al. Evidence of linkage between the serotonin transporter and autistic disorder. Mol Psychiatry. 1997;2:247-50.

96. Klauck SM, Poustka F, Benner A, Lesch KP, Poustka A. Serotonin transporter (5-HTT) gene variants associated with autism? Hum Mol Genet. 1997;6:2233-8.

97. Vukicevic J, Siegel B. Pervasive developmental disorder in monozygotic twins. J Am Acad Child Adolesc Psychiatry. 1990;29:897-900.

98. Szatmari P. Heterogeneity and the genetics of autism. J Psychiatry Neurosci. 1999;24:159-65.

99. Salmon B, Hallmayer J, Rogers T, Kalaydjieva L, Petersen P, Nicholas $P$, et al. Absence of linkage and linkage disequilibrium to chromosome 15q11-q13 markers in 139 multiplex families with autism. Am J Med Genet. 1999;88:551-6.

100. Konstantareas MM, Homatidis S. Chromosomal abnormalities in a series of children with autistic disorder. J Autism Dev Disord. 1999;29:275-85.
101. Mesibov G. Current perspectives and issues in autism and adolescence. In: Schopler E, Mesibov G, editors. Autism in Adolescents and Adults. New York and London: Plenum Press; 1983. p. 37-53.

102. Vilensky J, Damasio A, Maurer R. Gait disturbances in patients with autistic behavior. Arch Neur. 1981;38:646-9.

103. Hallet M, Lebiedowska M, Thomas S, Stanhope S, Denckla M, Rumsey J. Locomotion of autistic adults. Arch Neurol. 1993;50:1304-8.

104. Meiselas K, Spencer E, Oberfield R. Differentiation of stereotypes from neuroleptic-related dyskenisias in autistic children. J Clin Psychopharmacol. 1989;9:207-9.

105. Tuchman RF, Rapin I, Shinnar S. Autistic and dysphasic children. II: Epilepsy. Pediatrics. 1991;88:1219-25.

106. Volkmar F, Nelson D. Seizure disorders in autism. J Am Acad Child Adolesc Psychiatry. 1990;29:127-9.

107. Gillberg C. Outcome in autism and autistic-like conditions. J Am Acad Child Adolesc Psychiatry. 1991;30:375-82.

108. Deykin E, MacMahon B. The incidence of seizures among children with autistic symptoms. Am J Psychiatry. 1979;136:1310-12.

109. Ballaban-Gil K, Rapin I, Tuchman R, Freeman K, Shinnar S. The risk of seizures in autistic individuals: occurrence of a secondary peak in adolescence. Epilepsia. 1991;32 Suppl 3:84.

110. Goulding P, Mendez S, Gibbons V, Hansen D, Kotagal S. The relationship between alterations in sleep architecture and daytime neuropsychological functions. Ann Neur. 1993;34:504.

111. Anderson LT, Campbell M, Grega DM, Perry R, Small AM, Green WH. Haloperidol in the treatment of infantile autism: effects on learning and behavioral symptoms. Am J Psychiatry. 1984;141:1195-202.

112. Anderson LT, Campbell M, Adams P, Small AM, Perry R, Shell J. The effects of haloperidol on discrimination learning and behavioral symptoms in autistic children. J Autism Dev Disord. 1989;19:227-39.

113. McCracken JT, McGough J, Shah B, Cronin P, Hong D, Aman MG, et al. Risperidone in children with autism and serious behavioral problems. N Engl J Med. 2002;347:314-21.

114. McDougle C, Kem D, Posey D. Case series: use of ziprazidone for maladaptive symptoms in youths with autism. ] Am Acad Child Adolesc Psychiatry. 2002;41:921-7.

115. Malone RP, Cater J, Sheikh RM, Choudhury MS, Delaney MA. Olanzapine versus haloperidol in children with autistic disorder: an open pilot study. J Am Acad Child Adolesc Psychiatry. 2001;40:887-94.

116. Kemner C, Willemsen-Swinkels SH, de Jonge M, Tuynman-Qua $H$, van Engeland $H$. Open-label study of olanzapine in children with pervasive developmental disorder. J Clin Psychopharmacol. 2002;22:455-60.

117. Allison D, Casey D. Antipsychotic-induced weight gain: a review of the literature. J Clin Psychiatry. 2001;62:22-31.

118. Ratzoni G, Gothelf D, Brand-Gothelf A, Reidman J, Kikinzon L, Gal G, et al. Weight gain associated with olanzapine and risperidone in adolescent patients: a comparative prospective study. J Am Acad Child Adolesc Psychiatry. 2002;41:337-43.

119. Correll C, Parikh U, Kane J, Malhotra A. Atypical antipsychoticinduced nutritional and metabolic effects during development. AACAP Scientific Proceedings; 2003. p. 129-30.

120. Brasic JR, Barnett JY, Sheitman BB, Tsaltas MO. Adverse effects of clomipramine [letter]. J Am Acad Child Adolesc Psychiatr. 1997;36:1165-6.

121. Gordon CT, State RC, Nelson JE, Hamburger SD, Rapoport JL. A double-blind comparison of clomipramine, desipramine, and placebo in the treatment of autistic disorder. Arch Gen Psychiatry. 1993; 50:441-7.

122. Buchsbaum MS, Hollander E, Haznedar MM, Tang C, SpiegelCohen J, Wei TC, et al. Effect of fluoxetine on regional cerebral metabolism in autistic spectrum disorders: a pilot study. Int J Neuropsychopharmacol. 2001;4:119-25.

123. McDougle C, Kresch L, Posey D. Repetitive thoughts and behavior in pervasive developmental disorders: treatment with serotonin reuptake inhibitors. J Autism Dev Disorders. 2000;30:427-35.

124. King $B H$, Wright DM, Handen BL, Sikich L, Zimmerman AW, McMahon W, et al. Double-blind, placebo-controlled study of amantidine hydrochloride in the treatment of children with autistic disorder. J Am Acad Child Adolesc Psychiatry. $2001 ; 40 ; 658-65$. 
125. Belsito KM, Law PA, Kirk KS, Landa RJ, Zimmerman AW. Lamotrigine therapy for autistic disorder: a randomized, doubleblind, placebo-controlled trial. J Autism Dev Disord. 2001;31:175-81.

126. McCormick L. Treatment with buspirone in a patient with autism. Arch Fam Med. 1997;6:368-70.

127. Gilman J, Tuchman R. Autism and associated behavioral disorders: pharmacotherapeutic intervention. Ann Pharmacother. 1995;29:47-56.

128. Pfeiffer SI, Norton J, Nelson L, Shott S. Efficacy of vitamin B6 and magnesium in the treatment of autism: a methodology review and summary of outcomes. J Autism Dev Disord. 1995;25:481-93.

129. Findling RL, Maxwell K, Scotese-Wojtila L, Huang J, Yamashita $T$, Wiznitzer M. High-dose pyridoxine and magnesium administration in children with autistic disorder: an absence of salutary effects in a double-blind, placebo-controlled study. J Autism Dev Disord. 1997;27:467-78.

130. Horvath K, Stefanatos G, Sokolski KN, Wachtel R, Nabors L, Tildon JT. Improved social and language skills after secretin administration in patients with autistic spectrum disorders. J Assoc Acad Minor Phys. 1998;9:9-15.

131. Nass R, Petrucha D. Acquired aphasia with convulsive disorder: a pervasive developmental disorder variant. J Child Neurol. 1990;5:327-8.

132. Plioplys A. Autism: electroencephalogram abnormalities and clinical improvement with valproic acid. Arch Pediatr Adolesc Med. 1994;148:220-2.

133. Stefanos GA, Grover W, Geller E. Case study: corticosteroid treatment of language regression in pervasive developmental disorder. J Am Acad Child Adolesc Psychiatry. 1995;34:1107-11.

134. Nass R, Gross A, Wisoff J, Devinsky O. Outcome of multiple subpial transections for autistic epileptiform regression. Pediatr Neurol. 1999;21:464-70.

135. Neville BG, Harkness WF, Cross JH, Cass HC, Burch VC, Lees JA, et al. Surgical treatment of severe autistic regression in childhood epilepsy. Pediatr Neurol. 1997;16:137-40.
136. Szabo CA, Wyllie E, Dolske M, Stanford LD, Kotagal P, Comair YG. Epilepsy surgery in children with pervasive developmental disorder. Pediatr Neurol. 1999;20:349-53.

137. Lewine JD, Andrews R, Chez M, Patil AA, Devinsky O, Smith M, et al. Magnetoencephalographic patterns of epileptiform activity in children with regressive autism spectrum disorders. Pediatrics. 1999;104:405-18.

138. Tuchman R, Gilman J. Pharmacotherapy of pervasive developmental disorders. Int Pediatr. 1993;8:211-18.

139. Lotter V. Follow-up studies. In: Rutter M, Schopler E, editors. Autism. A Reappraisal of Concepts and Treatment. New York: Plenum Press; 1978. p. 475-495.

140. Gillberg C, Steffenburg S. Outcome and prognostic factors in infantile autism and similar conditions: A population-based study of 46 cases followed through puberty. J Autism Dev Disord. 1987;17:273-87.

141. Wing L. Autistic adults. In: Gilberg C, editor. Diagnosis and Treatment of Autism. New York: Plenum Press; 1989. p. 419-32.

142. Paul R. Natural history. In: Cohen D, Donellan A, editors. Handbook of Autism and Pervasive Developmental Disorders. New York: John Wiley; 1987. p. 121-130.

143. Kobayashi R, Murata T, Yoshinaga K. A follow-up study of 201 children with autism in Kyushu and Yamaguchi areas, Japan. J Autism Dev Disord. 1992;22:395-411.

144. McEachin JJ, Smith T, Lovaas OI. Long-term outcome for children with autism who received early intensive behavioral treatment. Am J Ment Retard. 1993;97:359-91.

Corresponding author:

Newra T. Rotta

Rua Luiz Gonzaga, 650

CEP 90470-280 - Porto Alegre, RS, Brazil

Tel.: + 55 (51) 3328.7541

E-mail: nrotta@terra.com.br 